BMJ Open Sport \& Exercise Medicine

\section{Obesity and elevated blood pressure in suburban student athletes}

To cite: Georgeson A, Lebenthal M, Catania R, et al. Obesity and elevated blood pressure in suburban student athletes. BMJ Open Sport \& Exercise Medicine 2017;3:e000276. doi:10.1136/ bmjsem-2017-000276

Accepted 5 October 2017

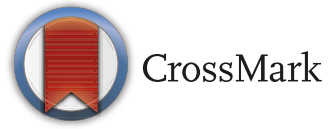

${ }^{1}$ Pediatrics, Penn State College of Medicine, Hershey, Pennsylvania, USA ${ }^{2}$ Department of Cardiology, Robert Wood Johnson University Hospital Somerset, Somerville, New Jersey, USA

Correspondence to Dr Steven Georgeson; georgeson1969@gmail.com

\section{ABSTRACT}

Objective To assess the prevalence of obesity and elevated blood pressure in a suburban population of middle school and high school student athletes and examine the differences from the previously published populations. Study design The Student Athlete Cardiac Evaluation Registry Study is a single-centre, community hospitalbased registry study, that provided free annual preparticipation physical examinations (PPE) from 2009 to 2017. The PPE on the 906 athletes included a history, a physical examination and body metrics including height, weight and blood pressure. The blood pressure was measured with an automated blood pressure cuff and, if elevated, was remeasured using a manual blood pressure cuff with aneroid manometer. The data from the PPE were collected and analysed for prevalence of obesity, overweight and elevated blood pressure measurements. Results The prevalence of obesity was $11 \%$, and $19 \%$ of participants were overweight. Many of the athletes had an elevated blood pressure (15\%). There was a significant association $(\mathrm{P}<0.001)$ between weight and elevated blood pressure. Among athletes with elevated blood pressure, $50 \%$ were either obese or overweight.

Conclusions There was a similar prevalence of overweight athletes in our study compared with previously published populations, but there were a lower proportion of obese athletes, which may be explained by differences in demographics. Despite the differences in study populations and the lower rate of obesity, the proportion of athletes with elevated blood pressure in our study was similar to prior populations. Weight issues and elevated blood pressure affect athletes across a range of different populations.

\section{INTRODUCTION}

Childhood obesity and hypertension have become major public health concerns in the last 30 years. According to the National Health and Nutrition Examination Survey in 2013-2014, the prevalence of obesity in children ages 2-19 years was $17 \%$. $^{1}$ The prevalence is rising in this age group, when compared with the same data from 1999 to $2000 .^{1}$ Adolescents have the largest proportion of obesity among other paediatric age groups. ${ }^{1}$ Studies on adolescents have shown that being obese confers an increased risk for the development of cardiovascular morbidities. $^{23}$ One of the cardiovascular morbidities is the development of hypertension, which has an overall prevalence of $2 \%-5 \%$ in childhood. ${ }^{45}$ The prevalence of elevated blood pressure has
What are the new findings?

- First study to assess a purely suburban predominantly Caucasian student athlete population.

- Lower prevalence of obesity than other student athlete populations that are predominantly AfricanAmerican but closer to the overall prevalence of childhood obesity in the USA.

- Similar prevalence of overweight student athletes compared with other populations.

- Despite lower prevalence of obesity, similar rate of elevated blood pressure compared with other populations.

been steadily rising in children and adolescents since the 1980 s and follows a rise in obesity. ${ }^{6}$

Among adolescents, there are close to 8 million high school students who participate in organised sports every year, ${ }^{7}$ and 49 of 50 states require some form of preparticipation physical examination (PPE) to be cleared for play. ${ }^{8}$ Many groups include an ECG and an echocardiogram (Echo) during the PPE to assess the student's risk for sudden cardiac arrest. While there is a lot of controversy over whether the ECG and the Echo should be included, the PPE may be an excellent public health tool for screening adolescents for obesity and hypertension. This was the purpose of several recent studies that showed a high prevalence of both obesity and elevated blood pressure in this population. A study from Kropa et al took place in an urban setting with a majority African-American population, and a study by Stiefel $e t a l^{10}$ was performed in a mixed urban and suburban setting, also with a majority African-American population. The purpose of this study was to understand the prevalence of obesity and elevated blood pressure in a suburban environment and examine the differences from the previous two studies.

\section{METHODS}

\section{Participants}

From 2009 to 2017, the Departments of Cardiology and Community Health at Robert Wood Johnson University Hospital Somerset, 
a community hospital based in Central New Jersey with a majority suburban population, ran an annual screening for the local high school and middle school athletes to determine risk for sudden cardiac arrest. Informed consent to participate in the study was obtained, and the consent form was signed by the student's parent or guardian.

\section{Study protocol}

Each athlete was given a questionnaire to complete based on the New Jersey State Interscholastic Athletic Association Annual Athletic PPE form. ${ }^{11}$ This form included sections regarding symptoms, medical history, medications and family history including history of sudden cardiac death. Age, self-reported race and ethnicity, school, grade and type of sport were all recorded. Body metrics were obtained by registered nurses trained in cardiology or by family practice residents. Vital signs, including height, weight, heart rate and blood pressure, were measured. The blood pressure was measured in all athletes with an automated blood pressure cuff. If the blood pressure was elevated, it was remeasured using a manual blood pressure cuff with aneroid manometer by the nurse, the physician or both. A comprehensive physical examination was performed by a board certified cardiologist. Cardiac examination included auscultation and an ECG. An Echo was performed if there were cardiac symptoms, a family history of heart disease, an abnormal physical examination (including an elevated blood pressure) or an abnormal ECG (based on the Seattle criteria of EKG interpretation in athletes). ${ }^{12}$

\section{Data analysis}

Participants' demographics, height, weight, blood pressures and body mass index (BMI) were all included for further analysis. Participants who did not have every one of these categories completed were not included in analysis. Blood pressures were considered either elevated or normal. Elevated blood pressures were those above the 95th percentile based on the athlete's age, sex and stature as stated in The Fourth Report on the Diagnosis, Evaluation and Treatment of High Blood Pressure in Children and Adolescents. ${ }^{13}$ Participants with an elevated blood pressure were not considered to have hypertension because of the nature of this study and the lack of ability for follow-up readings on two separate occasions needed to make the diagnosis. Participants with elevated blood pressures were instructed to follow up with their primary care doctors. BMI was classified as either normal, overweight or obese. Obese was considered greater than or equal to the 95th percentile based on the 2000 Centers for Disease Control and Prevention growth charts. ${ }^{14}$ Overweight was considered greater than or equal to the 85th percentile but below the 95th percentile for age and sex. Descriptive statistics were used to characterise BMI classifications, elevated blood pressure classifications and compare the groups with one another. A $\chi^{2}$ test of dependence was
Table 1 Demographics of study population

\begin{tabular}{|ll|}
\hline Total participants & 906 \\
\hline Age, mean \pm SD & $15.6 \pm 1.31$ \\
\hline Age by year & $(\mathrm{n}(\%))$ \\
\hline 13 & $18(2)$ \\
\hline 14 & $174(19)$ \\
\hline 15 & $271(30)$ \\
\hline 16 & $210(23)$ \\
\hline 17 & $135(15)$ \\
\hline 18 & $90(10)$ \\
\hline 19 & $8(1)$ \\
\hline Sex & $(\mathrm{n}(\%))$ \\
\hline Male & $628(70)$ \\
\hline Female & $278(30)$ \\
\hline Ethnicity & $(\mathrm{n}(\%))$ \\
\hline Caucasian & $687(76)$ \\
\hline Asian & $57(6)$ \\
\hline Hispanic & $61(7)$ \\
\hline African-American & $36(4)$ \\
\hline Other or unreported & $65(7)$ \\
\hline Height (in), mean \pm SD & $66.9 \pm 3.6$ \\
\hline Weight $($ lbs), mean $\pm S D$ & $146 \pm 31.6$ \\
\hline BMI, mean $\pm S D$ & $23.3 \pm 9.1$ \\
\hline Normal $(\mathrm{n}(\%))$ & $634(70)$ \\
\hline Overweight $(\mathrm{n}(\%))$ & $173(19)$ \\
\hline Obese $(\mathrm{n}(\%))$ & $99(11)$ \\
\hline Elevated blood pressure & $138(15)$ \\
\hline$>95$ th percentile $(\mathrm{n}(\%))$ & \\
\hline B & \\
\hline
\end{tabular}

BMI, body mass index.

performed to assess the relationship between BMI classification and elevated blood pressure.

\section{RESULTS}

Nine hundred and six athletes participated in the 9-year study. Athletes ranged from 13 to 19 years old, with an average age of 15.6 years. Seventy per cent of the athletes were male. Self-reported race and ethnicity data revealed that $76 \%$ were Caucasian, $6 \%$ were Asian, $7 \%$ were Hispanic and $4 \%$ were African-American (table 1).

Thirty per cent of the athletes were overweight or obese, with $11 \%$ classified as obese and $19 \%$ in the overweight category. One hundred and thirty-eight athletes $(15 \%)$ had an elevated blood pressure, representing greater than the 95th percentile for age, sex and stature (table 1). As the weight classification increased, the risk for elevated blood pressure rose steadily (table 2). In addition, among the 138 athletes with elevated blood pressure, $50 \%$ were either classified as overweight or obese. Specifically, $27 \%$ of the participants (37 of 138) were obese and 23\% (32 of 138) were overweight. 
Table 2 Weight classification of participants and the risk for elevated blood pressure

\begin{tabular}{ll}
\hline Weight classification & Risk for elevated blood pressure \\
\hline Normal weight & $10.8 \%(69 / 634)$ \\
Overweight & $18.5 \%(32 / 173)$ \\
Obese & $37.3 \%(37 / 99)$ \\
\hline
\end{tabular}

To further analyse the effect of weight classification on elevated blood pressure, a $\chi^{2}$ test of dependence was used. The relationship was statistically significant, $X^{2}$ $(2)=17.52, \mathrm{P}<0.001$, demonstrating that increased weight classification (ie, comparing normal weight to overweight or overweight to obese) increases the chance of having elevated blood pressure.

\section{DISCUSSION}

Typically, athletes are viewed by the general population as a healthy group of people who, through regular exercise, are able to negate the effects of a modern American lifestyle. The results in this study suggest that adolescent athletes are not as healthy as common opinion would suggest. There were high rates of overweight and obese individuals, as well as elevated blood pressure in this population. The prevalence of these metrics was high, and there was a correlation between being overweight and/or obese and having an elevated blood pressure.

In comparison with the PPE studies conducted by Kropa et at and Stiefel $e t a l,{ }^{10}$ this study's population was much different. Seventy-six per cent of the athletes in this study were Caucasian compared with $16 \%$ and $32 \%$, respectively, in Kropa et at and Stiefel et al. ${ }^{10}$ In contrast, this study included only $4 \%$ African-Americans, compared with $71 \%$ and $66 \%$ in the other populations (table 3).

While there were a similar proportion of overweight athletes (19\% in our study vs $20 \%$ in Kropa et at and $20 \%$ in Stiefel et $a l^{10}$, there were a lower proportion of obese athletes ( $11 \%$ in the current study vs $24 \%$ in Kropa et $a l^{\ominus}$ and $23 \%$ in Stiefel $\left.e t a l\right) .{ }^{10}$ The lower proportion of obese athletes may be explained by differences in demographics. Our study population was much more Caucasian and less African-American than the other two populations. In addition, our study population was a purely suburban one. The prevalence of obesity in our study $(11 \%)$ is more representative of the general US paediatric population. In 2015, the prevalence of childhood obesity in the USA was $12.7 \% .{ }^{15}$ Despite the differences in study populations and the lower rate of obese athletes, the proportion of athletes with blood pressure above the 95th percentile in our study (15\%) was similar to Kropa et a $\hat{\ell}^{\ominus}(14.8 \%)$ and Stiefel $e t a l^{10}(21 \%)$ (table 3). Kropa et a ${ }^{\ominus}$ demonstrated that there was a linear increase in the risk of elevated blood pressure with the increase in weight Our study echoed the findings from Kropa $e t a t$ and showed that with increasing weight classification, there was a statistically significant increased risk for elevated blood pressure. This suggests that overweight individuals as well as obese individuals each have an important contribution to the increase in childhood hypertension.

\begin{tabular}{|c|c|c|c|}
\hline Study & Current study & Kropa et $a l^{9}$ & Stiefel et $a l^{10}$ \\
\hline Years & 2009-2017 & 2009-2012 & 2009-2013 \\
\hline Setting & $\begin{array}{l}\text { Central New Jersey, } \\
\text { suburban }\end{array}$ & $\begin{array}{l}\text { Philadelphia, } \\
\text { Pennsylvania, urban }\end{array}$ & $\begin{array}{l}\text { Jackson, Mississippi, } \\
\text { urban+suburban }\end{array}$ \\
\hline Total, N & 906 & 2678 & 7705 \\
\hline Age, mean (years) & 15.6 & 15.5 & 15.5 \\
\hline \multicolumn{4}{|l|}{ Sex $(\%)$} \\
\hline Male & 70 & 69 & 69 \\
\hline Female & 30 & 31 & 31 \\
\hline \multicolumn{4}{|l|}{ Race/ethnicity (\%) } \\
\hline Caucasian & 76 & 16 & 32 \\
\hline African-American & 4 & 71 & 66 \\
\hline Hispanic & 7 & 5 & 1.2 \\
\hline Asian & 6 & 7 & 0.5 \\
\hline \multicolumn{4}{|c|}{ Weight classification (\%) } \\
\hline Obese & 11 & 24 & 23 \\
\hline Overweight & 19 & 20 & 20 \\
\hline Obese+overweight & 30 & 44 & 43 \\
\hline \multicolumn{4}{|l|}{ Blood pressure } \\
\hline >95th percentile & 15 & 14.8 & 21 \\
\hline
\end{tabular}


It is well known that African-Americans have a higher prevalence of hypertension in adulthood. ${ }^{16}$ Compared with Kropa et al, ${ }^{9}$ with a predominantly urban African-American population, this study with a predominantly suburban Caucasian population demonstrated a similar prevalence of elevated blood pressure above the 95th percentile. This finding highlights the relevance of elevated blood pressure in all communities and among all races and ethnicities in the USA. Even if there is a national trend for increased elevated blood pressures in African-Americans, it is still important to recognise it is an issue in other racial groups as well.

Limitations to this study include the inability to diagnose patients with elevated blood pressure as having hypertension due to the lack of follow-up measurements over several weeks. This would lower the actual incidence of hypertension compared with a one-time elevated blood pressure. In addition, this study was compared with Stiefel $e t a l^{10}$ and Kropa et $a l^{9}{ }^{9}$ both of which had larger sample sizes. All three studies were regional and limited by the composition of their populations. A true assessment of obesity and elevated pressure would require a national study with more equal racial proportions and representing a variety of living environments. There is also an inherent risk of using BMI to classify weight status as a measure for total body fat. The risk is particularly higher in a population of athletes who are more likely to have higher proportion of fat-free mass, which may cause their BMIs to be falsely elevated.

In conclusion, this study is unique in that, to the best of our knowledge, it is the first study to assess a purely suburban, predominantly Caucasian student athlete population. As such, the prevalence of obesity is lower, but the number of participants who were overweight or who had elevated blood pressure was similar in our population to those populations with more urban and African-American students. In addition, there was an association between excess weight and elevated blood pressure in our population, similar to previous studies. Therefore, this study adds to the growing data showing that excess weight and elevated blood pressure exist across diverse populations, even in the most active of populations-the student athlete population.

Acknowledgements The authors would like to thank Stephanie Sawon, Margaret Legue, Martha Travostino, Yong Tao and Diane Rutkowski from the Department of Cardiology, Robert Wood Johnson University Hospital/Somerset for their assistance and expertise in conducting the screening studies. In addition, the authors would like to thank Serena Collado, Maria Cermenaro and Cory Georgeson from the Department of Community Health, Robert Wood Johnson University Hospital/ Somerset for administration, recruitment and data collection. Lastly, the authors would like to thank the Robert Wood Johnson University Hospital/Somerset family practice residency program for the use of their facilities for the screenings and for the residents who assisted in the screenings.

Competing interests None declared.

Ethics approval Institutional Review Board from the Robert Wood Johnson Medical School.

Provenance and peer review Not commissioned; externally peer reviewed.

Open Access This is an Open Access article distributed in accordance with the Creative Commons Attribution Non Commercial (CC BY-NC 4.0) license, which permits others to distribute, remix, adapt, build upon this work non-commercially, and license their derivative works on different terms, provided the original work is properly cited and the use is non-commercial. See: http://creativecommons.org/ licenses/by-nc/4.0/

(C) Article author(s) (or their employer(s) unless otherwise stated in the text of the article) 2017. All rights reserved. No commercial use is permitted unless otherwise expressly granted.

\section{REFERENCES}

1. Ogden CL, Carroll MD, Fryar CD, et al. Prevalence of obesity among adults and youth: United States, 2011-2014. 219, 2015:1-8.

2. Must $A$, Jacques PF, Dallal GE, et al. Long-term morbidity and mortality of overweight adolescents. A follow-up of the Harvard Growth Study of 1922 to 1935. N Engl J Med 1992;327:1350-5.

3. Saydah S, Bullard KM, Imperatore G, et al. Cardiometabolic risk factors among US adolescents and young adults and risk of early mortality. Pediatrics 2013;131:e679-86.

4. Shapiro DJ, Hersh AL, Cabana MD, et al. Hypertension screening during ambulatory pediatric visits in the United States, 2000-2009. Pediatrics 2012;130:604-10.

5. Sorof JM, Lai D, Turner J, et al. Overweight, ethnicity, and the prevalence of hypertension in school-aged children. Pediatrics 2004;113:475-82.

6. Din-Dzietham R, Liu Y, Bielo MV, et al. High blood pressure trends in children and adolescents in national surveys, 1963 to 2002. Circulation 2007;116:1488-96.

7. National Federation of State High School Associations. 20152016 Sports participation survey. 2016 http://www.nfhs.org/ ParticipationStatistics/PDF/2015-16_Sports_Participation_Survey. pdf (accessed 23 Feb 2017)

8. Caswell SV, Cortes N, Chabolla M, et al. State-specific differences in school sports preparticipation physical evaluation policies. Pediatrics 2015;135:26-32.

9. Kropa J, Close J, Shipon D, et al. High prevalence of obesity and high blood pressure in urban student-athletes. $J$ Pediatr 2016;178:194-9.

10. Stiefel EC, Field L, Replogle W, et al. The prevalence of obesity and elevated blood pressure in adolescent student athletes from the state of Mississippi. Orthop J Sports Med 2016;4:232596711662936.

11. New Jersey State Interscholastic Athletic Association. Preparticipation physical evaluation form. 2017 http://www.njsiaa. org/forms-information (accessed 24 Feb 2017).

12. Drezner JA, Ackerman MJ, Anderson J, et al. Electrocardiographic interpretation in athletes: the 'Seattle criteria'. Br J Sports Med 2013;47:122-4.

13. National High Blood Pressure Education Program Working Group on High Blood Pressure in Children and Adolescents. The fourth report on the diagnosis, evaluation, and treatment of high blood pressure in children and adolescents. Pediatrics 2004;114:555-76.

14. Centers for Disease Control and Prevention. CDC growth charts. 2016 http://www.cdc.gov/growthcharts/cdc_charts.htm.

15. Afshin A, Forouzanfar MH, Reitsma MB, et al. Health effects of overweight and obesity in 195 countries over 25 years. N Engl J Med 2017;377:13-27.

16. Hertz RP, Unger AN, Cornell JA, et al. Racial disparities in hypertension prevalence, awareness, and management. Arch Intern Med 2005;165:2098-104. 